\title{
Microstructure and microhardness of Ti-48Al alloy prepared by rapid solidification
}

\author{
Xiao-yu Chen ${ }^{1,2}$, Hong-ze Fang', *Qi Wang', Shu-yan Zhang ${ }^{3}$, Rui-run Chen', Yan-qing Su' \\ 1. School of Materials Science and Engineering, Harbin Institute of Technology, Harbin 150001, China \\ 2. School of Electromechanic Engineering, Qingdao University, Qingdao 266071, China \\ 3. Centre of Excellence for Advanced Materials, Songshan Lake, Dongguan 523808, China
}

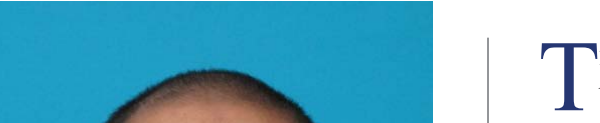

Abstract: To improve the microstructure and microhardness, Ti-48Al (at.\%) alloy was rapidly solidified by melt spinning under different cooling rates. The microstructure and microhardness of rapidly solidified Ti-48Al alloy were systematically investigated. Results show that the average lamellar colony size of the alloy reduces from $60.6 \mu \mathrm{m}$ to $11 \mu \mathrm{m}$ as the cooling rate increases from $2.3 \times 10^{5}$ to $5.1 \times 10^{5} \mathrm{~K} \cdot \mathrm{s}^{-1}$, caused by the increase of nucleation rate at a higher cooling rate. At the high cooling rate of (4.3$5.1) \times 10^{5} \mathrm{~K} \cdot \mathrm{s}^{-1}$, the $\alpha$ phase is the primary phase, and a few metastable $\alpha$ phases are reserved, which then transform into $\alpha_{2}$ phase and subsequently lead to the formation of $\alpha_{2}$ equiaxed grain. The lamellar spacing also decreases with the increase of cooling rate. The relationship between lamellar spacing $(d)$ and cooling rate $(v)$ is $d=33.6 v^{-1.34}$. The microhardness increases with the increase of cooling rate because the refined lamellar spacing and grain size can improve the microhardness.

Key words: cooling rate; solidification path; microstructure; lamellar spacing; microhardness

CLC numbers: TG146.23; Document code: A; Article ID: 1672-6421(2020)06-429-06

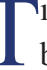
Al-based alloys exhibit the superiority of light-weight for application in aeroengine blades, due to their high specific strength, low density, excellent oxidation resistance and creep resistance ${ }^{[1-5]}$. However, the as-cast TiAl alloys with large columnar lamellar $\left(\alpha_{2}+\gamma\right)$ grains have poor room-temperature ductility and low fracture toughness ${ }^{[6,7]}$. Therefore, it is necessary to reduce the grain size for improving mechanical properties of the alloy. The rapid solidification technique could reduce the grain size and lamellar spacing of the alloy, obtain refined microstructure and more excellent properties than conventional solidification ${ }^{[8,9]}$. The Ti-48Al based alloys with nearly lamellar microstructure exhibit balanced strength and ductility, and the typical Ti-48Al based alloy of Ti-48Al-2Nb-2Cr has been used in aircraft engines ${ }^{[10,11]}$. However, Ti-48Al-2Nb-2Cr alloy with large columnar grains limits its high-temperature applications ${ }^{[12]}$. The rapid solidification technique shows a promise for improving the microstructure of Ti-48Al based alloys, which is worthy of study ${ }^{[10,12]}$.

Alloys prepared by chill-block melt-spinning method are suitable for rapid solidification and subsequent cooling at small melt pool dimensions ${ }^{[13-15]}$, where the ribbons show a flatness surface and a thin thickness. In this study, the rapid solidification technique of chill-block melt-spinning was used to prepare the binary Ti-48Al alloy. The phases constitution, lamellar spacing and microhardness are analyzed. An attention is given to the solidification paths of the rapidly solidified Ti-48Al alloy.

\section{Materials and experimental methods}

The as-cast ingots with the nominal compositions of Ti-48Al alloy were prepared from aluminum $(>99.9 \%$, wt.\%) and titanium sponge $(>99.9 \%$, wt. $\%)$ by vacuum consumable arc-melting. The weight of each button ingot is about $120 \mathrm{~g}$, and every button ingot 
was remelted six times. The weight loss rate of button ingots obtained by melting is less than $0.5 \%$. The specimens were cut into smaller pieces using the wire-electrode for melt spinning process. The wheel used for melt spinning was made of copper. Different speeds of the wheel can be set to get different solidification rates. The cooling rates were calculated by the Newton heat transfer model in the sample interface. Table 1 shows the physical parameters of the Ti-48Al alloy used for calculating cooling rates. Images captured through the silicon wafer by high-speed infrared imaging revealed that the ribbon formation is controlled by thermal transport ${ }^{[16]}$. The cooling rate of rapid solidification is usually measured by calculation of the counting rate of heat flow in Newton's cooling mode ${ }^{[17,18]}$. It shows the cooling rate linearly increases with an increase in wheel speed.

The optical microscope (OM) specimens of conventional casting and rapid solidification alloys were polished and etched using the reagent of $5 \% \mathrm{HF}+5 \% \mathrm{HNO}_{3}+90 \% \mathrm{H}_{2} \mathrm{O}$ (volume fraction), and the transmission electron microscopy (TEM) specimens were etched using Kroll's reagent composed of 28 vol.\% HF, 2vol.\% $\mathrm{HNO}_{3}$ and 70 vol. $\% \mathrm{H}_{2} \mathrm{O}$. The phase constitution and crystal structure were analyzed by $\mathrm{D} / \mathrm{max}-\mathrm{rB}$ $\mathrm{X}$-ray diffractometer (XRD) at the scanning speed of 10 degrees per minute. The microstructure was investigated by optical microscopy (Olympus GX71 OM), scanning electron microscopy (SEM-BSE, Merlin Compact) and TEM (Tecnai G2 F30). The microhardness was examined using the HVS-1000 digital microhardness tester.

Table 1: Physical parameters of Ti-48Al alloy (at.\%)

\begin{tabular}{cccccc}
$\begin{array}{c}\text { Wheel temperature } \\
(\mathbf{K})\end{array}$ & $\begin{array}{c}\text { Droplet temperature } \\
(\mathbf{K})\end{array}$ & $\begin{array}{c}\text { Heat-transfer coefficient } \\
\left(\mathbf{W} \cdot \mathbf{m}^{-2} \cdot \mathbf{K}^{-1}\right)\end{array}$ & $\begin{array}{c}\text { Specific heat } \\
\left(\mathbf{J} \cdot \mathbf{k g}^{-1} \cdot \mathbf{K}^{-1}\right)\end{array}$ & $\begin{array}{c}\text { Density } \\
\left(\mathbf{k g} \cdot \mathbf{m}^{-3}\right)\end{array}$ & $\begin{array}{c}\text { Width } \\
(\boldsymbol{\mu m})\end{array}$ \\
\hline 293 & 1,832 & 105 & 799 & 3,744 & $96.9-143.2$
\end{tabular}

\section{Results and discussion}

\subsection{Microstructure of conventional casting alloy}

According to the phase diagram of binary TiAl alloy ${ }^{[19]}$, the solidification path of Ti-48Al follows $\mathrm{L} \rightarrow \mathrm{L}+\beta \rightarrow \mathrm{L}+\alpha \rightarrow \alpha \rightarrow \alpha+\gamma$ $\rightarrow \alpha_{2}+\gamma$. XRD results show that the alloy consists of $\alpha_{2}$ and $\gamma$ phases, as shown in Fig. 1. Figure 2 shows the OM and SEM microstructures of conventional casting Ti-48Al alloy. The conventional casting Ti-48Al alloy exhibits the typical fully lamellar microstructure. The average lamellar colony size is $600 \mu \mathrm{m}$ (equivalent to the grain size), tested using the linear intercept method.

\subsection{Microstructure of rapidly solidified alloy}

Figure 3 shows the OM microstructure of rapidly solidified Ti-48Al alloys. The lamellar colony size decreases with an increase in cooling rate, and the average lamellar colony size measured using the linear intercept method is shown in Fig. 4. The average lamellar colony size is $61 \mu \mathrm{m}$ under the cooling rate of $2.3 \times 10^{5} \mathrm{~K} \cdot \mathrm{s}^{-1}$, but decreases to $11 \mu \mathrm{m}$ when the cooling

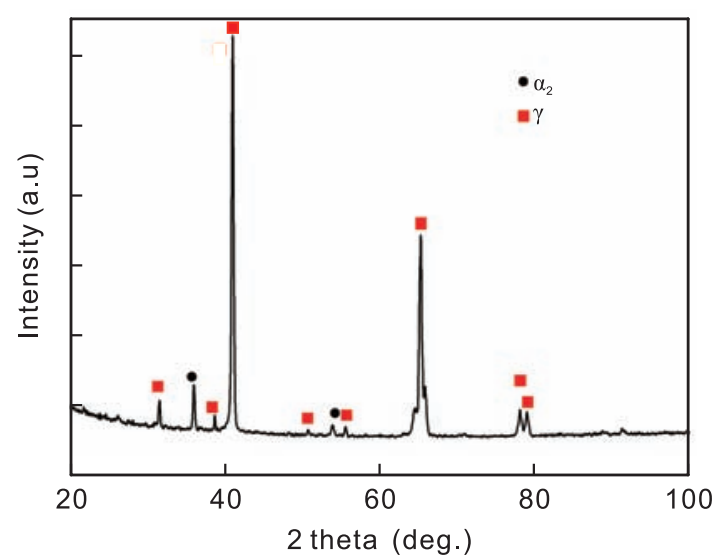

Fig. 1: XRD pattern of conventional casting Ti-48Al alloy

rate increases to $5.1 \times 10^{5} \mathrm{~K} \cdot \mathrm{s}^{-1}$.

The obvious decrease of grain size with the increase in cooling rate is related to the supercooling. The supercooling degree has a significant influence on the nucleation rate and growth rate of grains during solidification, and the increase of
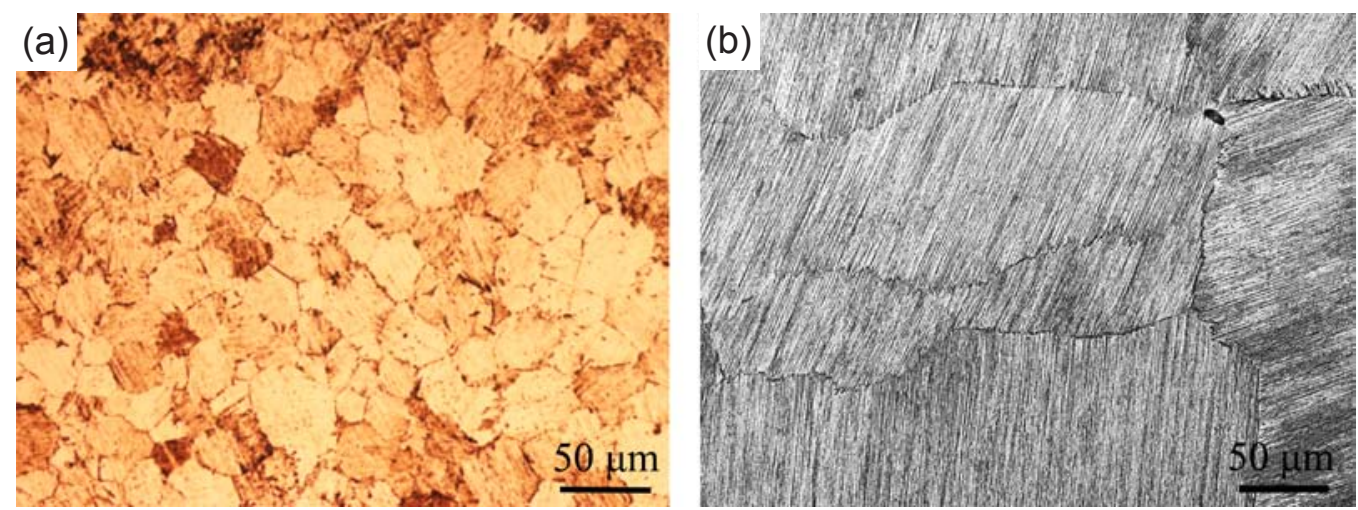

Fig. 2: OM and SEM microstructures of conventional casting Ti-48Al alloy 

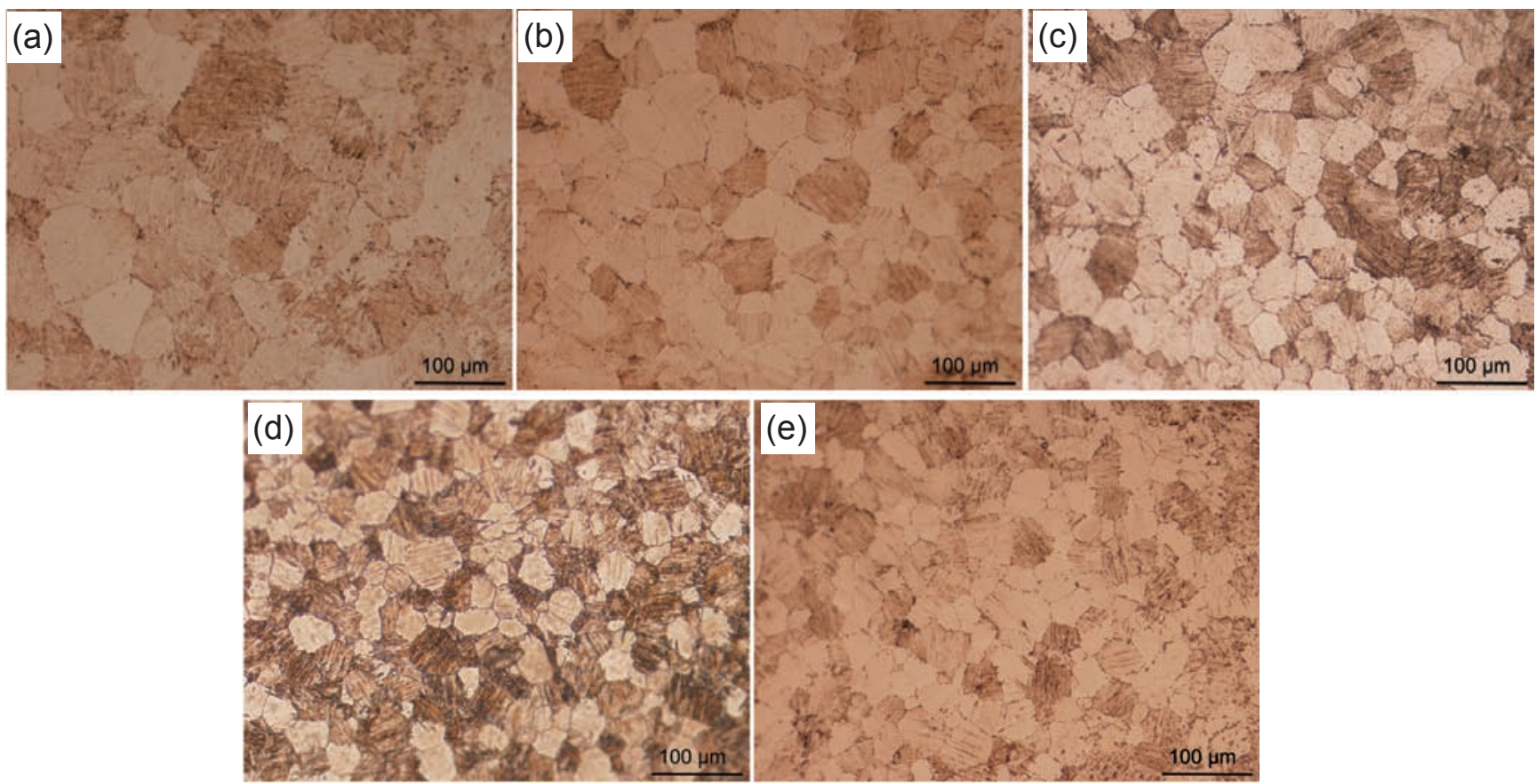

Fig. 3: OM microstructures of rapidly solidified Ti-48Al alloy under different cooling rates: (a) $2.3 \times 10^{5} \mathrm{~K} \cdot \mathrm{s}^{-1}$; (b) $3.6 \times 10^{5} \mathrm{~K} \cdot \mathrm{s}^{-1}$; (c) $4.3 \times 10^{5} \mathrm{~K} \cdot \mathrm{s}^{-1}$; (d) $4.9 \times 10^{5} \mathrm{~K} \cdot \mathrm{s}^{-1}$; (e) $5.1 \times 10^{5} \mathrm{~K} \cdot \mathrm{s}^{-1}$

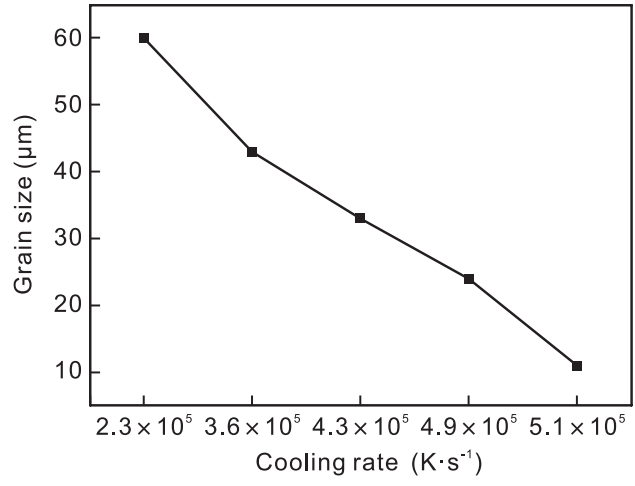

Fig. 4: Effect of cooling rate on average grain size of Ti-48Al alloy

supercooling degree in a certain range can lead to the increase in nucleation rate and growth rate ${ }^{[13,16]}$. In the conventional casting alloy, the slope of growth rate is higher than the slope of nucleation rate; in the rapid solidification alloys, the slope of nucleation rate is higher than the slope of growth rate ${ }^{[18]}$. In this study, the rapid solidification cooling rates is at the range of $(2.3-5.1) \times 10^{5} \mathrm{~K} \cdot \mathrm{s}^{-1}$, which leads to a great supercooling degree. Therefore, with the increase of cooling rate, the slope of nucleation rate is higher than the slope of growth rate, which leads to colony size decreases.

Figure 5 shows the SEM microstructure of rapidly solidified alloys prepared under different cooling rates. The fully lamellar microstructure can be observed under the cooling rates of $2.3 \times 10^{5}$ and $3.6 \times 10^{5} \mathrm{~K} \cdot \mathrm{s}^{-1}$, which is similar to the conventional casting alloy. The near lamellar microstructures can be observed under the cooling rates of $(4.3-5.1) \times 10^{5} \mathrm{~K} \cdot \mathrm{s}^{-1}$, which are composed of $\alpha_{2}$ equiaxed grains and lamellar colonies. The content of $\alpha_{2}$ equiaxed grains increases with the increase of cooling rate, as shown in Fig. 6.

\subsection{Solidification path of rapidly solidified alloy}

When the TiAl alloy is prepared under a high cooling rate, the primary phase is remained to room temperature. According to the phase diagram of binary TiAl alloy, the $\beta$ phase is the primary phase, and no $\alpha_{2}$ equiaxed grains exist in the final microstructure in the equilibrium solidification of TiAl alloy ${ }^{[6]}$. However, under the cooling rates of (4.3$5.1) \times 10^{5} \mathrm{~K} \cdot \mathrm{s}^{-1}$, many $\alpha_{2}$ equiaxed grains exist in the matrix, and their content increases with the increase of cooling rates. This is because that at the high cooling rate of $(4.3-5.1) \times 10^{5} \mathrm{~K} \cdot \mathrm{s}^{-1}$, the rapidly solidified alloy experiences a supercooling, and the $\alpha$ phase is the primary phase at the high cooling rate ${ }^{[12-14]}$. Most of the metastable $\alpha$ phases transformed into the $\alpha_{2}+\gamma$ lamellar structure, and some of the metastable $\alpha$ phase was reserved, which then orderly transformed into $\alpha_{2}$ phase, leading to the formation of $\alpha_{2}$ equiaxed grains. Based on the above analysis, the solidification path of rapidly solidified Ti-48Al alloy under the cooling rates of $(4.3-5.1) \times 10^{5} \mathrm{~K} \cdot \mathrm{s}^{-1}$ is $\mathrm{L} \rightarrow \mathrm{L}+\alpha \rightarrow \alpha \rightarrow \alpha+$ $(\alpha+\gamma)_{\text {lamellae }} \rightarrow \alpha_{2}+\left(\alpha_{2}+\gamma\right)_{\text {lamellae }}$.

\subsection{Lamellar spacing}

Figure 7(a) shows the TEM lamellar structure of conventional casting Ti-48Al alloy, which was viewed under the edgeon position (the lamellae are perpendicular to the direction of observation). The thickness of $\gamma$ lamella is much larger than that of $\alpha_{2}$ lamella, which agrees with the equilibrium solidification diagram of TiAl alloy. Figure 7(b) shows the TEM lamellar structure of the rapidly solidified Ti-48Al alloy. The thickness of $\alpha_{2}$ lamella is close to the thickness of $\gamma$ lamella. The content of $\alpha_{2}$ lamella of the rapidly solidified Ti$48 \mathrm{Al}$ alloy is much higher than that of conventional casting Ti$48 \mathrm{Al}$ alloy due to the phase transformation of $\alpha \rightarrow(\alpha+\gamma)_{\text {lamellae }}$ 

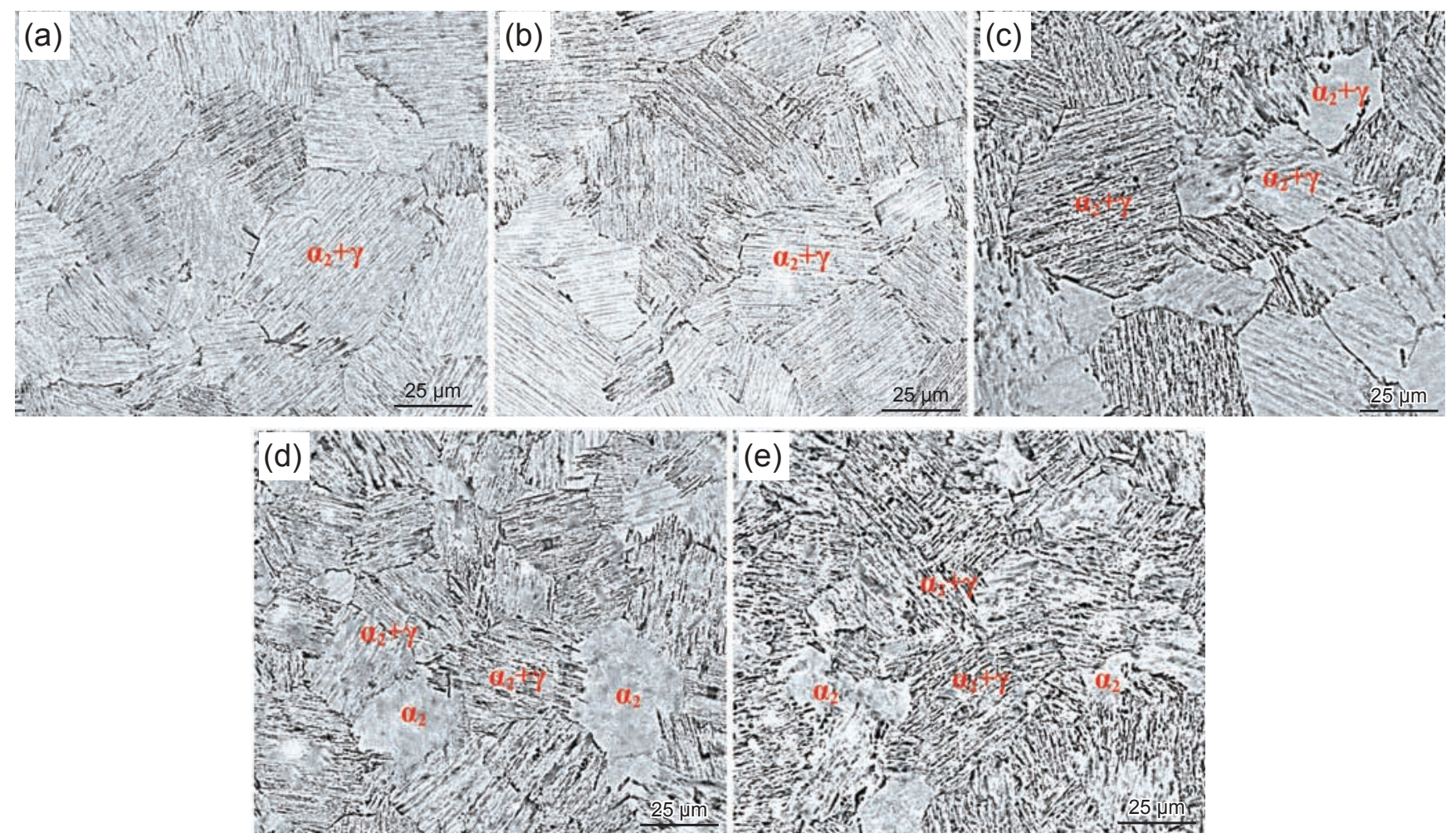

Fig. 5: Microstructures of rapidly solidified Ti-48Al alloy under different cooling rates: (a) $2.3 \times 10^{5} \mathrm{~K} \cdot \mathrm{s}^{-1}$; (b) $3.6 \times 10^{5} \mathrm{~K} \cdot \mathrm{s}^{-1}$; (c) $4.3 \times 10^{5} \mathrm{~K} \cdot \mathrm{s}^{-1}$; (d) $4.9 \times 10^{5} \mathrm{~K} \cdot \mathrm{s}^{-1}$; (e) $5.1 \times 10^{5} \mathrm{~K} \cdot \mathrm{s}^{-1}$

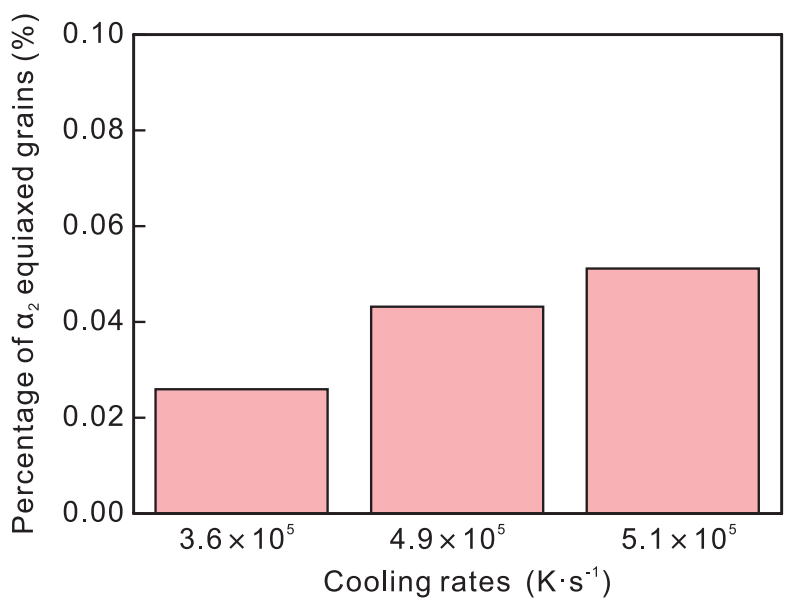

Fig. 6: Content of $\alpha_{2}$ equiaxed grain under different cooling rates

not being completed during the rapid solidification.

In this study, the thicknesses of lamellar spacing were measured when the lamellae were viewed under the edgeon position. The average lamellar spacing of the conventional casting Ti-48Al alloy is $330 \mu \mathrm{m}$. Figure 8 (a) shows the statistical measurement of lamellar spacing of the rapidly solidified Ti$48 \mathrm{Al}$ alloy. It can be seen that the lamellar spacing decreases with the increase of cooling rate. The previous research ${ }^{[20]}$ shows that the relationship of lamellar spacing $(d)$ and the cooling rate $(v)$ in the lamellar region of the TiAl alloys can be expressed as:

$$
d=k v^{\mathrm{m}}
$$

where, $k$ is the material constant and $m$ is the velocity exponent, and thus according to the regression analysis of the experiment data, the function relationship between lamellar

$$
\begin{aligned}
d & =33.6 v^{-1.34} \\
r^{2} & =0.988
\end{aligned}
$$

spacing $(d)$ and cooling rate $(v)$ can be described as follows: where $r^{2}$ is the regression coefficient. The linear functional relationship of interlamellar spacing and cooling rate after logarithm conversion is shown in Fig. 8(b).

\subsection{Microhardness of conventional casting and rapidly solidified alloys}

Figure 9 shows the statistical measurement of microhardness of conventional casting and rapidly solidified Ti-48Al alloys. It is noted that the microhardness of rapidly solidified $\mathrm{Ti}$ $48 \mathrm{Al}$ alloy is higher than that of conventional casting Ti-48Al alloy, and the microhardness of rapidly solidified Ti-48Al alloy increases with the increase of cooling rate. The Ti-48Al alloy with higher cooling rate exhibits the greater microhardness for the three reasons: (1) The microhardness in the lamellar region is mainly affected by the lamellar spacing, and the microhardness of rapidly solidified Ti-48Al alloy increases with the decreasing of lamellar spacing ${ }^{[9]}$. (2) The grain size of rapidly solidified alloy decreases with the increasing of cooling rate, and the microhardness increases with the decrease of grain size according to the Hall-Petch equation. (3) The 

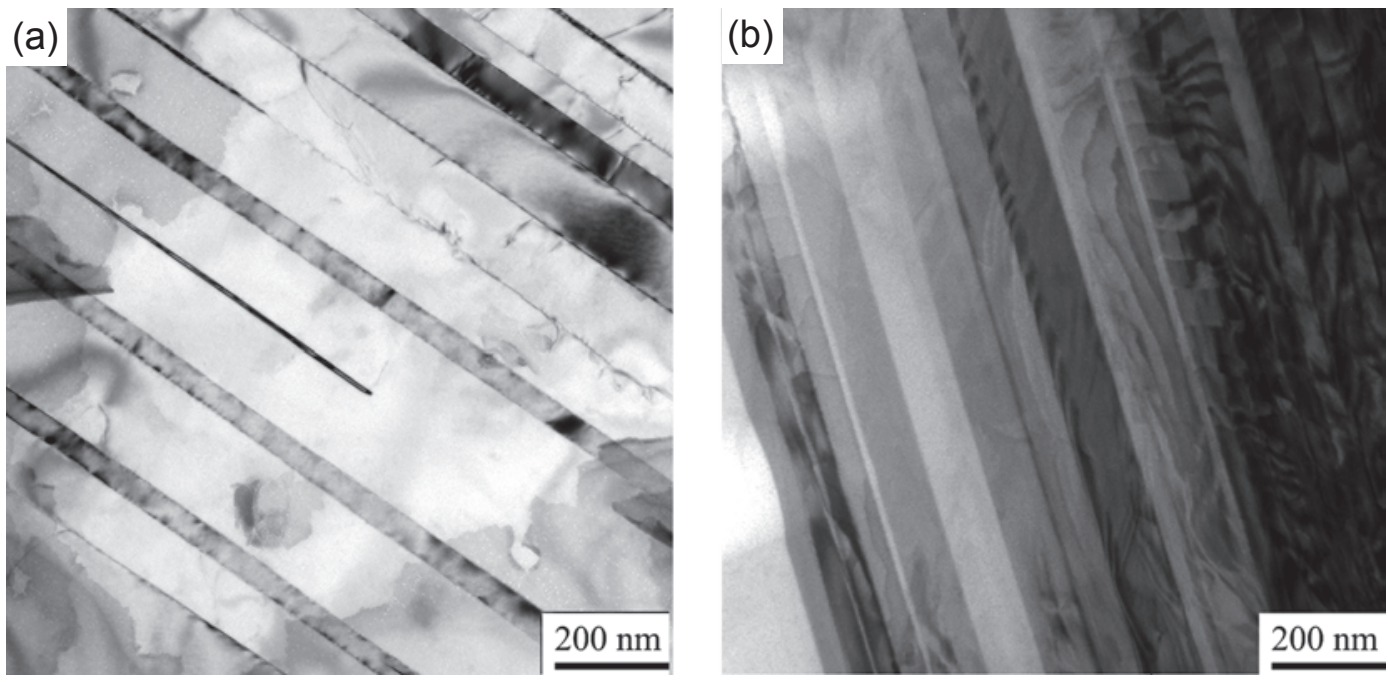

Fig. 7: TEM images of Ti-48Al alloy: (a) conventional casting alloy and (b) rapid solidification prepared under the cooling rate of $5.1 \times 10^{5} \mathrm{~K} \cdot \mathrm{s}^{-1}$
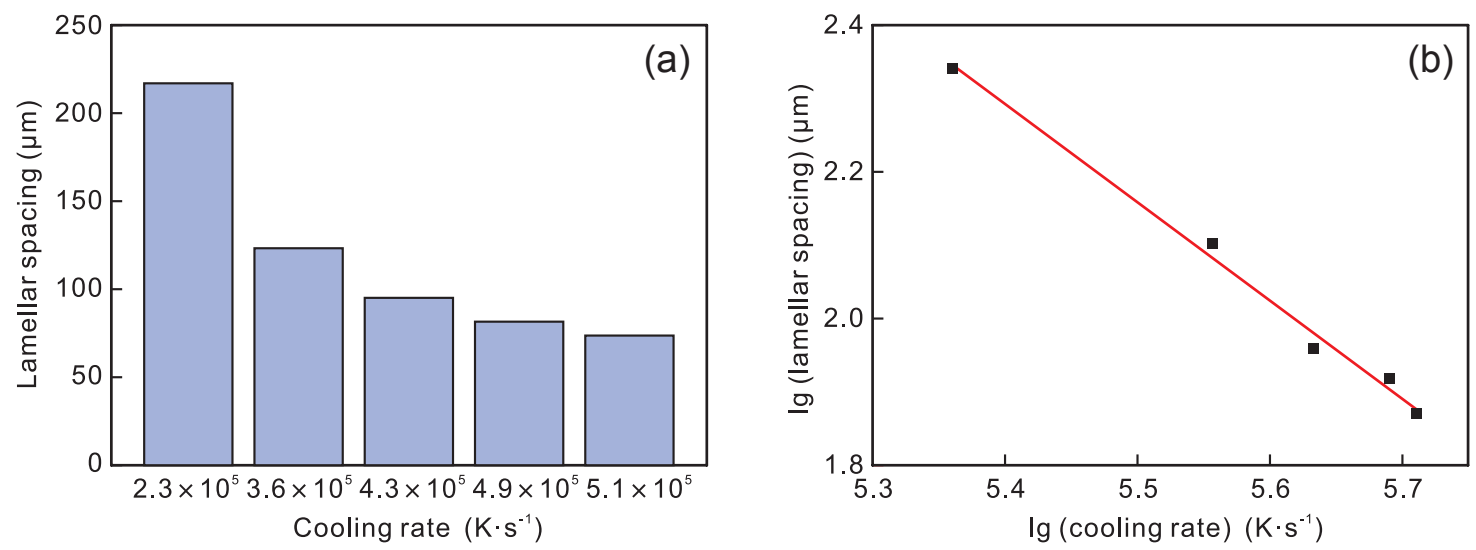

Fig. 8: Effect of cooling rates on lamellar spacing of Ti-48Al alloy: (a) lamellar spacing at different cooling rates and (b) linear function relationship of lamellar spacing and cooling rate after logarithm conversion

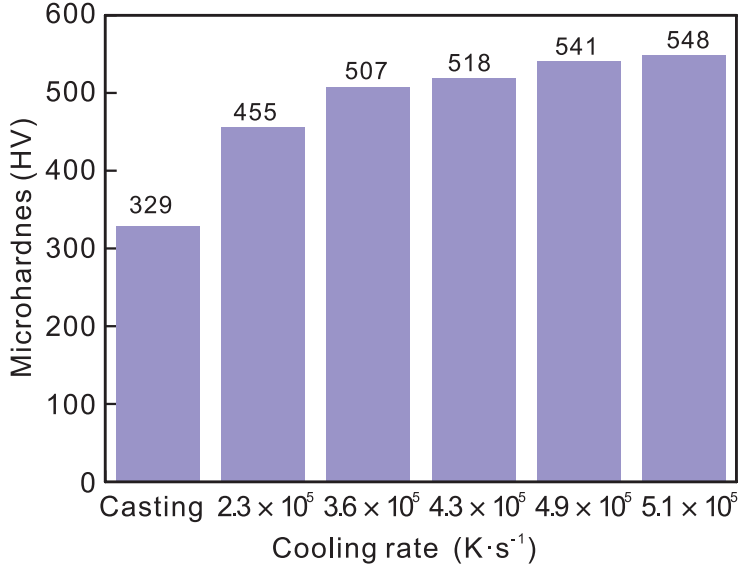

Fig. 9: Microhardness of conventional casting and rapidly solidified Ti-48Al alloy

phase transformation of $\alpha \rightarrow(\alpha+\gamma)_{\text {lamellae }}$ is not complete due to the rapid solidification, which increases the proportion of $\alpha_{2}$ lamellae in $\alpha_{2}+\gamma$ lamellar structure. Therefore, the thickness of $\alpha_{2}$ lamellae closes to the thickness of $\gamma$ lamellae, as shown in Fig. 7(b), which improves the structure stability of $\alpha_{2}+\gamma$ lamellae.

\section{Conclusions}

(1) The average lamellar colony size reduces from 61 to $11 \mu \mathrm{m}$ as the cooling rate increases from $2.3 \times 10^{5}$ to $5.1 \times 10^{5} \mathrm{~K} \cdot \mathrm{s}^{-1}$, due to the increase of the nucleation rate at high cooling rate.

(2) At the high cooling rate of $(4.3-5.1) \times 10^{5} \mathrm{~K} \cdot \mathrm{s}^{-1}$, the $\alpha$ phase is the primary phase, and some metastable $\alpha$ phases are reserved, which then orderly transform into $\alpha_{2}$ phase, leading to the formation of $\alpha_{2}$ equiaxed grains. The solidification path is $\mathrm{L} \rightarrow \mathrm{L}+\alpha \rightarrow \alpha \rightarrow \alpha+(\alpha+\gamma)_{\text {lamellae }} \rightarrow \alpha_{2}+\left(\alpha_{2}+\gamma\right)_{\text {lamellae. }}$.

(3) The lamellar spacing decreases with the increase of cooling rate, and the functional relationship between lamellar spacing $(d)$ and cooling rate $(v)$ can be described as $d=33.6 v^{-1.34}$.

(4) The rapid solidification can reduce the lamellar spacing and lamellar colony size, which improves the microhardness of Ti-48Al alloy. 


\section{Acknowledgements}

This work was financially supported by the National Natural Science Foundation of China (Grant No. 51825401), the China Postdoctoral Science Foundation (Grant No. 2019TQ0076) and the Program for Guangdong Introducing Innovative and Entrepreneurial Teams (Grant No. 2016ZT06G025).

\section{References}

[1] Wei D X, Koizumi Y, Nagasako M, et al. Refinement of lamellar structures in Ti-Al alloy. Acta Materialia, 2017, 125: 81-97.

[2] Wang $Q$, Chen R R, Yang $Y Y$, et al. High-throughput analysis of $\mathrm{Al}$ and $\mathrm{Nb}$ effects on mechanical behaviour of TiAl alloys using electromagnetic cold crucible continuous casting. Journal of Alloys \& Compounds, 2019, 775: 124-131.

[3] Yang J P, Wang X Y, Cao B, et al. Tailoring the microstructure of a $\beta$-solidifying TiAl alloy by controlled post-solidification isothermal holding and cooling. Metallurgical \& Materials Transactions A, 2017, 48: 5095-5105.

[4] Dong S L, Liu T, Li Y J, et al. Hot deformation processing capability of Fe-contained high $\mathrm{Nb}$ TiAl-based alloy. Vacuum, 2019, 159: 391-399.

[5] Jiang Z H, Zhao C Z, Yu J J, et al. Effect of Cr on microstructure and oxidation behavior of TiAl-based alloy with high Nb. China Foundry, 2018, 15(1): 17-22.

[6] Ohnuma I, Fujita Y, Mitsui $\mathrm{H}$, et al. Phase equilibria in the Ti-A binary system. Acta Materialia, 2000, 48(12): 3113-3123.

[7] Gao Z, Yang J, Wu Y, et al. A newly generated nearly lamellar microstructure in cast Ti-48Al-2Nb-2Cr alloy for high-temperature strengthening. Metallurgical and Materials Transactions A, 2019, 50(12): 100169.

[8] Sokolovsky V S, Stepanov N D, Zherebtsov S V, et al. The effect of $\mathrm{Gd}$ addition on the kinetics of $\alpha_{2} \rightarrow \gamma$ transformation in Y-TiAl based alloys. Intermetallics, 2020, 120: 106759.

[9] Appel H F, Paul J D, Oehring H M. Gamma Titanium Aluminide Alloys: Science and Technology, Wiley-VCH, 2011.
[10] Chen G, Peng Y B, Zheng G, et al. Polysynthetic twinned TiAl single crystals for high-temperature applications. Nature Materials, 2016, 15: 876.

[11] Clemens H, Mayer S. Intermetallic titanium aluminides in aerospace applications-processing, microstructure and properties. Materials at High Temperatures, 2016, 33(4-5): $1-11$.

[12] Kan W, Chen B, Peng $\mathrm{H}$, et al. Formation of columnar lamellar colony grain structure in a high $\mathrm{Nb}$-TiAl alloy by electron beam melting. Journal of Alloys and Compounds, 2019, 809: 151673.

[13] Kim W T, Cantor B. The variation of grain size with cooling rate during melt spinning. Scripta Metallurgica et Materialia, 1990, 24(4): 633-637.

[14] Jones $\mathrm{H}$. Cooling rates during rapid solidification from a chill surface. Materials Letters, 1996, 26(3): 133-136.

[15] Çadırlı E, Kaya H, Gündüz M. Effect of growth rates and temperature gradients on the lamellar spacing and the undercooling in the directionally solidified $\mathrm{Pb}-\mathrm{Cd}$ eutectic alloy. Materials Research Bulletin, 2003, 38(9-10): 1457-1476.

[16] Nagashio K, Kuribayashi K. Experimental verification of ribbon formation processing chill-block melt spinning. Acta Materialia, 2006, 54(9): 2353-2360.

[17] Lavernia E J, Srivatsan T S. The rapid solidification processing of materials: science, principles, technology, advances, and applications. Journal of Materials Science, 2010, 45(2): 287325.

[18] Liu Z G, Chai L H, Chen $Y$ Y. Effect of cooling rate and $Y$ element on the microstructure of rapidly solidified TiAl alloys. Journal of Alloys and Compounds, 2010, 504S: S491-S495.

[19] Schuster J C, Palm M. Reassessment of the binary aluminumtitanium phase diagram. Journal of Phase Equilibria \& Diffusion, 2006, 27(3): 255-277.

[20] Dong S L, Chen R R, Guo J J, et al. Effect of power on microstructure and mechanical properties of Ti44Al6Nb1.0Cr2.0V0.15Y0.1B alloy prepared by cold crucible directional solidification. Materials \& Design, 2015, 67: 390-397.

[21] Jin Z, Gray G T. On deformation twins and twin-related lamellae in TiAl. Journal of Materials Science, 1998, 33(1): $77-$ 83. 